\title{
Electrochemical techniques and sensors for ocean research
}

\author{
G. Denuault \\ School of Chemistry, University of Southampton, Southampton, SO17 1BJ, UK \\ Received: 31 July 2009 - Published in Ocean Sci. Discuss.: 20 August 2009 \\ Revised: 7 December 2009 - Accepted: 9 December 2009 - Published: 17 December 2009
}

\begin{abstract}
This paper presents a review of applications of electrochemical methods in ocean sensing. It follows the white paper presented at the OceanSensors08 workshop held at the Leibniz-Institut für Ostseeforschung, Warnemünde, Germany, from 31 March to 4 April 2008. The principles of electrochemical techniques are briefly recalled and described. For each technique, relevant electrochemical sensors are discussed; known successful deployments of electrochemical sensors are recalled; challenges experienced when taking sensors from the research lab to the field are raised; future trends in development and applications are proposed and assessed for their potential for oceanographic applications; where possible technological readiness levels are estimated. The document is supported with references drawn from both the electrochemical and oceanographic literature.
\end{abstract}

\section{Introduction}

Electrochemical methods are routinely used in analytical chemistry. Also known as electroanalytical techniques, they have been developed for measurements in the laboratory, mostly for fundamental research. This is a mature field of research with dedicated journals, in particular the Journal of Electroanalytical Chemistry (started in 1959), Electroanalysis (started in 1989) and Electrochemistry Communications (started in 1999). A few of these techniques successfully operate outside the labs and have acquired such an importance that several key environmental parameters would be hard to measure differently. In aquatic systems oxidation-reduction potentials (ORP) and $\mathrm{pH}$ are measured by potentiometry (measurement of a potential), dissolved oxygen (DO) is measured by amperometry (measurement of a current), trace met-

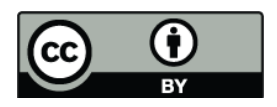

Correspondence to: G. Denuault (gd@ soton.ac.uk) als and speciation are measured by voltammetry (measurement of currents over a range of potentials) while conductivity and therefore salinity are measured by impedimetry (measurement of an electrical impedance). Electrochemical sensors are increasingly being investigated to perform measurements in situ for single or multiple analytes (Taillefert et al., 2000). Over the last twenty five years voltammetry has been successfully used with microelectrodes to determine the concentration and speciation of some redox species in situ (Luther et al., 1999). Microelectrodes have also been employed as amperometric sensors to control mass transport and alleviate the need for membranes (Prien et al., 2001, 2005; Sosna et al., 2007, 2008). Although promising on paper these approaches are only reported by a handful of research groups; none of the microelectrode systems has reached significant technology readiness levels, let alone commercialisation and routine use.

This article presents a brief review of electrochemical techniques and sensors, assesses their potential for oceanographic applications and estimates their level of readiness. The breadth of the topic is vast and the article is therefore intentionally limited to applications of electrochemical methods in the field. Combinations of electrochemical methods with other techniques such as liquid chromatography with amperometric or voltammetric detection, preparative electrochemical treatment of water samples prior to spectrophotometric analysis or electrochemical determination of end points during titrations are not included.

It is the opinion of the author and of others (Reimers, 2007) that the uptake of existing electroanalytical methods, the development of new electrochemical sensors and their successful application in ocean sensing are limited more by the lack of expertise in electrochemical methods than by technological hurdles (electrochemical systems tend to be cheap, easily manufactured, small and portable compared to other physicochemical devices). This situation is not new. In the preface of their book on Marine Electrochemistry

Published by Copernicus Publications on behalf of the European Geosciences Union. 
(Whitfield and Jagner, 1981) were already showing their concern: "... it is likely that the dramatic evolution of the microprocessor will change the nature of electroanalytical chemistry by enabling "intelligent" instruments to be developed that are capable of optimizing the analytical procedure to suit the nature of the sample. Such developments are already underway and there is a danger that they will transform the rather bewildering array of electrochemical procedures into a continuum of techniques that will be virtually incomprehensible to the non-specialists so that their potential for solving environmental problems might not be fully exploited." Their predictions did not entirely materialise. It is true that the power of electronics is now such that hand held field devices capable of performing an array of electroanalytical techniques are commercially available. However none is sufficiently "intelligent" to switch between techniques or optimise the procedure to suit the nature of the sample. Yet the array of electroanalytical methods is as bewildering now as it was in 1981 and the application of electrochemical sensors in ocean sensing therefore depends on educating students and established researchers to the intricacies of electrochemical systems. For this reason and also to stimulate discussion and engender new ideas for future developments and deployments of electrochemical oceanographic sensors, the article is purposely organised around the different electroanalytical methods. Attempts and successful applications of electrochemical methods to ocean sensing are presented along with relevant references. In the spirit of OceanSensors 08 which brought together scientists from many different fields, fundamental concepts are summarily defined to ensure accessibility to a general readership but references to seminal articles and key text books on the fundamentals of electrochemical methods are included.

\section{Overview of electrochemical techniques and electro- chemical sensing}

Electrochemistry is an interfacial science concerned with the interactions between chemical species and interfaces. Electrochemical processes occur at all kinds of interfaces ranging from those involving two phases such as solid-liquid, liquidliquid, liquid-gas and solid-gas interfaces to those involving three phases such as solid-liquid-gas interfaces. Electrochemical processes also take place at more complex interfaces such as biological membranes. All interfaces can be harnessed for analytical measurements and most have been investigated for sensor development. The reactions concerned in electrochemical processes are redox reactions which involve the oxidised and reduced forms of a species be it an ion, a molecule or a biological entity. Most cases correspond to the conversion of one form into another and therefore involve the transfer of electrons across the interface. The interface may be inert and thus only provide a suitable site for the reaction and a source or sink for the electrons but more often than not the interface participates in the reaction. In localised corrosion for example the same interface holds regions of the metal undergoing oxidation and therefore metal loss to the solution while other regions promote the reduction of dissolved oxygen with electrons being transferred by conduction within the metal from the oxidation to the reduction regions. In sensor development it is common to seek an inert (i.e. not participating as reactant in the redox process), but nevertheless sufficiently catalytically active, interface to speed up the reaction of interest. Electroanalytical techniques therefore harness the electrochemical relationship at the interface to establish a link between an electrical signal (current or voltage) and the presence of a chemical species in the vicinity of the electrode. In electrochemical sensing an electrode operates as a transducer which converts the property of a species in the analyte (its concentration, activity or flux) into an electrical signal. Depending on the technique used the output signal reflects any of the following quantities: the potential difference between an indicator electrode and a reference electrode, the current flowing between two electrodes or its integral over time (the charge passed) or the electrical impedance of the electrochemical cell. The species of interest may be neutral or ionic while the electrode may be bare or modified with a film. This film may range from a single molecular layer to several mm thick. Examples of materials used to modify electrodes include mercury for the polarographic determination of trace metals (Devitre et al., 1991), probably the most common electrode modification, conducting polymers (Dhawan et al., 1997), gels (Tercier-Waeber et al., 1998; Tercier-Waeber et al., 1999), polymers loaded with enzymes and redox mediators (Grundig et al., 1995; Bartlett et al., 1998; Cosnier et al., 1999), doped polymers (Trojanowicz et al., 1996), molecular constructions tethered to the electrode surface and nanostructured materials (Evans et al., 2002; Imokawa et al., 2006). The electrodes may be passive as in potentiometry or active as in amperometry and impedimetry. In potentiometry the indicator electrode is in equilibrium with the analyte while in amperometry or impedimetry the working electrode drives a reduction or an oxidation. In this case the reaction at the electrode consumes species from the analyte and produces new species in the analyte; the electron involved in the electrode reaction may therefore be viewed as a reagent that can be supplied (reduction) or taken away (oxidation). In amperometry and impedimetry the other electrode, often called the counter or secondary electrode, undergoes a reverse reaction to that on the working electrode (e.g. an oxidation if the working electrode runs a reduction) and therefore also alters the composition of the analyte. Depending on the technique the electrochemical cell involves a number of electrodes. Table 1 presents an overview of common electrode configurations while Table 2 presents a summary of the control parameters and signals measured for typical electrochemical sensing devices. In contrast to the other devices, potentiometric and self powered cells (the electrochemical reaction generates a current as 
Table 1. Overview of typical electrode configurations found in electrochemical systems: WE=Working electrode, $\mathrm{CE}=$ Counter electrode, $\mathrm{RE}=$ reference electrode, $\mathrm{CE} / \mathrm{RE}=$ counter electrode also acting as a reference electrode. $\mathrm{WE} / \mathrm{CE}=$ working electrode alternatively acting as a counter electrode.

\begin{tabular}{lcl}
\hline Technique & Number of electrodes & Electrode configurations \\
\hline Potentiometry & 2 & $\begin{array}{l}\text { Indicator electrode+RE } \\
\text { Indicator electrode+RE } \\
+ \text { common electrode }\end{array}$ \\
Amperometry or & 3 & $\mathrm{WE}+\mathrm{CE} / \mathrm{RE}$ \\
voltammetry & 3 & $\mathrm{WE}+\mathrm{CE}+\mathrm{RE}$ \\
& 4 & $2 \mathrm{WE}+1 \mathrm{CE}+1 \mathrm{RE}$ \\
& Arrays & $\mathrm{n} \mathrm{WE+1} \mathrm{CE+1} \mathrm{RE}$ \\
Impedimetry & 2 & $\mathrm{WE}+\mathrm{CE}$ or $2 \mathrm{WE} / \mathrm{CE}$ \\
& 3 & $\mathrm{WE}+\mathrm{CE}+\mathrm{RE}$ \\
& 4 & $2 \mathrm{WE}+2$ indicator electrodes \\
\hline
\end{tabular}

in a fuel cell) produce a signal without the need for driving circuitry.

Electrochemical sensors are generally electrochemical cells filled with liquid, polymer or even solid electrolytes as e.g. with high temperature zirconia in solid state gas sensors (Dubbe, 2003). Devices may also involve semiconductors as with ion selective field effect transistors (ISFET) (Shitashima et al., 2008) or enzyme FET (ENFET) (Kharitonov et al., 2000; Simonian et al., 2004). The separation of electrodes from the analyte ranges from no separation with microelectrodes to diffusion barriers for measurements in the gas phase, membranes for measurements in gases, liquids or in-vivo, gels for controlling fouling in aquatic systems (Tercier-Waeber et al., 1998) and ion selective glasses (Thomas, 1979) or resins for ion selective electrodes (ISE).

In general electrochemical sensors have electrodes with geometric areas ranging from a few square millimetres to a few square centimetres (although their electroactive area may be orders of magnitude larger depending on their surface roughness or porosity) but much smaller electrodes known as microelectrodes are increasingly used in electrochemical sensing, including in oceanographic applications. Put simply, a microelectrode is an electrode with micrometre dimensions. However one needs to consider the mode of operation to appreciate why micrometre size electrodes have acquired a special place in the electrochemical literature. Operated as potentiometric probes microelectrodes behave as their larger counterparts, i.e. the equation describing the potentiometric response is the same whatever the size of the electrode (though non idealities occur with sub-micrometre electrodes, in part because inhomogeneities in the electrode material and surface defects start to influence the electrode potential). Operated as amperometric probes microelectrodes behave differently depending on the size of the electrode and on the time scale of the measurement. In particular diffusion to and from a microelectrode depends on the geometry and size of the electrode as well as the timescale considered. The equations which describe the amperometric response of a micrometre size electrode are therefore different from those that apply to large electrodes. Hence electrochemists define microelectrodes as electrodes having a characteristic length sufficiently small (typically below $50 \mu \mathrm{m}$ ) that it determines their amperometric properties (Montenegro et al., 1991). The distinctive amperometric properties of microelectrodes have been harnessed to develop electrochemical oceanographic sensors; these will be reviewed in a section dedicated to the amperometric properties of microelectrodes.

The following sections consider each electrochemical technique in more details. Each section starts with a brief overview of the principles of the technique and continues with specific examples of sensors derived from the technique considered. Examples of application in marine environments are given and discussed. Where possible reviews dedicated to specific topics are referenced. The recent evolution of electrochemical sensors can be appreciated from the dedicated reviews published in Analytical Chemistry (Bakker and Telting-Diaz, 2002; Bakker, 2004; Bakker and Qin, 2006; Privett et al., 2008).

\section{Potentiometric methods}

\subsection{Principles}

The basic principle of potentiometry is that no current is allowed to flow between the electrodes. This ensures that the indicator electrode behaves as a passive probe (it does not consume or produce species) in thermodynamic equilibrium with the analyte. The potential of the indicator electrode is linearly related to the logarithm of the activity (or concentration if the solution is sufficiently dilute that activity coefficients can be considered as unity) of the species of interest. It is measured against that of a reference electrode, typically a saturated calomel electrode (SCE) or $\mathrm{Ag} / \mathrm{AgCl}$ electrode. For an excellent introduction to the fundamentals of electrode potentials see the book by (Compton and Sanders, 1996).

Several issues affect potentiometric methods: The electrode response is often slow $\left(t_{90} \geq 1 \mathrm{~s}\right)$. Interferences from other species are also common. Miniaturisation is tricky especially because the potential is not stable when the electrode approaches micrometre dimensions. Reference electrodes do not keep a perfectly stable potential and variations of circa $\pm 5 \mathrm{mV}$ are not uncommon. Over time the potential drifts, possibly because of temperature effects and changes in electrode surface. As a result, the response needs frequent calibration, often before and after the measurement of interest.

The key advantages of potentiometry are the selectivity of the signal to the analyte of interest, the ability to probe a large range of species not redox active in aqueous environments and the good detection limit. In an excellent review (De Marco et al., 2007) describe the applications of ion 
Table 2. Overview of electrochemical techniques. $E$ is the electrode potential, $i$ the current flowing between electrodes, $Q$ the charge passed (the integral of the current over time), $Z$ the electrical impedance of the electrochemical circuit. $f$ and $t$ are respectively the frequency and time of the potential perturbation. $c$ and $a$ are respectively the concentration and activity of the analyte of interest.

\begin{tabular}{lllll}
\hline Method & $\begin{array}{l}\text { Control } \\
\text { parameter }\end{array}$ & $\begin{array}{l}\text { Signal } \\
\text { measured }\end{array}$ & $\begin{array}{l}\text { Relation to } \\
\text { analyte }\end{array}$ & $\begin{array}{l}\text { Driving } \\
\text { circuitry required }\end{array}$ \\
\hline $\begin{array}{l}\text { Amperometry or } \\
\text { voltammetry }\end{array}$ & $\begin{array}{l}E=\text { fixed, stepped, } \\
\text { ramped }\end{array}$ & $i$ & $i \propto c$ & Yes \\
$\begin{array}{l}\text { Coulometry } \\
\begin{array}{l}\text { Impedimetry } \\
- \text { Conductimetric } \\
\text { sensing } \\
- \text { Capacitive }\end{array}\end{array}$ & $Q$ & $Q \propto c$ & Yes \\
$\begin{array}{l}\text { sensing } \\
\text { Potentiometry }\end{array}$ & $i=0$ & $Z$ & $Z \propto\left(\sum c\right)^{-1}$ & Yes \\
$\begin{array}{l}\text { Self-powered } \\
\text { electrochemical cells }\end{array}$ & $\begin{array}{l}\text { Chemistry, electrode } \\
\text { material }\end{array}$ & $i$ & $i \propto c$ & No \\
\hline
\end{tabular}

selective electrodes in natural waters. They discuss the merits and problems of different ISEs in the context of field measurements including strategies to develop remote use of ISEs for ocean sensing. Potentiometry with ion selective electrodes has improved significantly in recent years, notably by achieving very low detection limits. Current trends involve non equilibrium potentiometry and pulsed potentiometry, see for example the recent review by (Bakker and Pretsch, 2007). Because ISEs can probe a large range of ions, they are well suited to the development of electronic noses and tongues where an array of different sensors provides a chemical finger print of a given analyte. Because of the analogy with human taste and olfaction, most investigations focus on the analysis of food and drinks but a few articles do report the use of electronic tongues with environmental samples including sea water (Men et al., 2005; Hong et al., 2006; Rudnitskaya et al., 2008).

Some dissolved gas sensing electrodes operate in the potentiometric mode. These are essentially $\mathrm{pH}$ electrodes covered with a gas permeable membrane. The latter separates the analyte from the electrolyte where the measurement is carried out. The $\mathrm{pH}$ of the electrolyte therefore reflects the activity of the gas of interest in the analyte. Dissolved $\mathrm{CO}_{2}$ and $\mathrm{NH}_{3}$ have thus been sensed in sea water (Clegg and Whitfield, 1995).

\subsection{Potential selective electrodes}

The range of potential selective materials is large. Taking $\mathrm{pH}$ determination as an example one finds different solid state electrodes such as antimony oxide (Horrocks et al., 1993), iridium oxide (Marzouk et al., 1998; Wipf et al., 2000; Bezbaruah and Zhang, 2002; Hassan et al., 2002), tungsten oxide or palladium hydride (Imokawa et al., 2006) which provide a Nernstian response with $\mathrm{pH}$. Many potential selective electrodes rely on solid state membranes to provide selectivity. The best known is the glass electrode for protons but similar electrodes exist for sodium and fluoride (De Marco et al., 2007). Glass selective microelectrodes were popular with biologists in the early days of intracellular measurements (Thomas, 1979) and although it is still possible to find dedicated instruments such as micro-forges to prepare them, they tend to be replaced by selective cocktails of ionophores or liquid ion exchange resins. The latter have tended to be used with micrometre size ion selective electrodes, essentially for lab work since they are very fragile. Some electrodes, e.g. for hydrogen, calcium and potassium, are commercially available readily made. Alternatively, cocktails of ionophores are available, e.g. from Fluka. Because of their size these electrodes require regular calibrations. Such miniaturised electrodes could have applications in oceanography, especially with the development of microfluidics. However, pressure effects on the viscous resin separating the analyte from the internal reference compartment could limit deployment to shallow waters. High pressures require special sensor designs. In recent years successful deployments of potentiometric sensors have been reported for deep water operations, for example to monitor $\mathrm{pH}$, $\mathrm{H}_{2}$ and $\mathrm{H}_{2} \mathrm{~S}$ in hydrothermal vent fluids at high temperature (Ding and Seyfried, 2007; Ding et al., 2001) and to monitor the $\mathrm{pH}$ of biological communities in the in the vicinity of hydrothermal vents (Le Bris et al., 2001). These cases illustrate the difficulties involved in designing and proofing reliable potentiometric devices capable of sustaining the high pressure and temperatures found near the vents. They also illustrate the strategies developed to circumvent issues such as drift in the sensor response, calibrations and variations in internal reference electrode potential. 
Table 3. Common chronoamperometric techniques with the potential waveforms and corresponding amperometric responses typical of diffusion controlled processes.

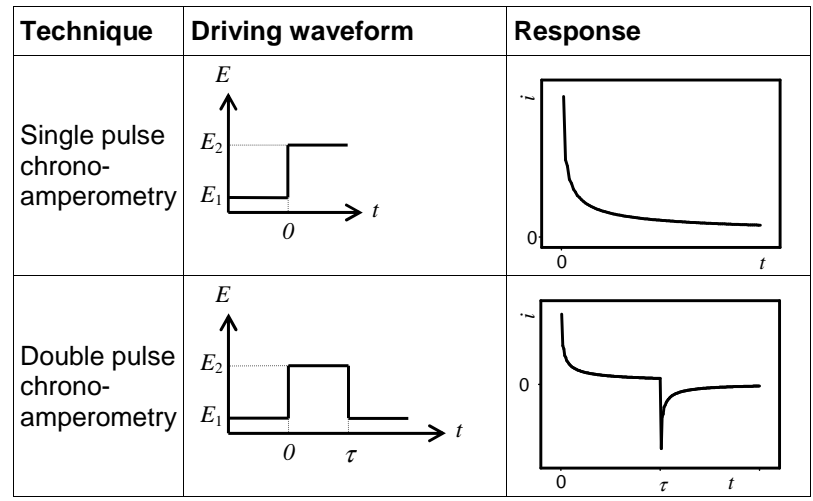

Solid electrodes have been modified with various materials to provide a specific potentiometric response, e.g. with conducting polymers (Bobacka et al., 2003) or with PVC membranes loaded with a carbonate selective host for the determination of oceanic carbon dioxide (Choi et al., 2002). Novel electrode modifications providing ion selectivity are continuously being reported (Bakker and Telting-Diaz, 2002; Bakker, 2004; Bakker and Qin, 2006; Privett et al., 2008). Possible developments could come from advancements in supramolecular chemistry and the design of new host-guest chemistries (Gale, 2008). Novel host molecules are being synthesised offering new avenues for potentiometric detection. However the transfer of these molecules to working sensors is very slow; often selectivity and sensitivity are limited. Significant enhancements in ion selective electrodes are expected from the development of bioelectrochemical sensors. These are considered in a dedicated section below.

\section{Amperometric methods}

\subsection{Principles}

A potential (the electrochemical driving force) is applied to the working electrode to select the species that will undergo redox reaction(s) and the current (the rate of the reaction(s)) is measured. In the simplest form of amperometry, the current is measured at a fixed potential under steady state conditions. The latter occur when the transport of the species of interest to the electrode or the kinetics of the electrode reaction are independent of time. This is the basis for simple sensors where the current is proportional to the concentration of the species of interest; a typical example is the Clark electrode where the diffusion of oxygen across a membrane imposes steady state mass transport conditions (Whitfield and Jagner, 1981). Many amperometric methods employ potential waveforms to provide additional information. The simplest waveform is a single potential step from a value where
Table 4. Common voltammetric techniques based on analog potential ramps shown with the corresponding amperometric responses typical of diffusion controlled processes.

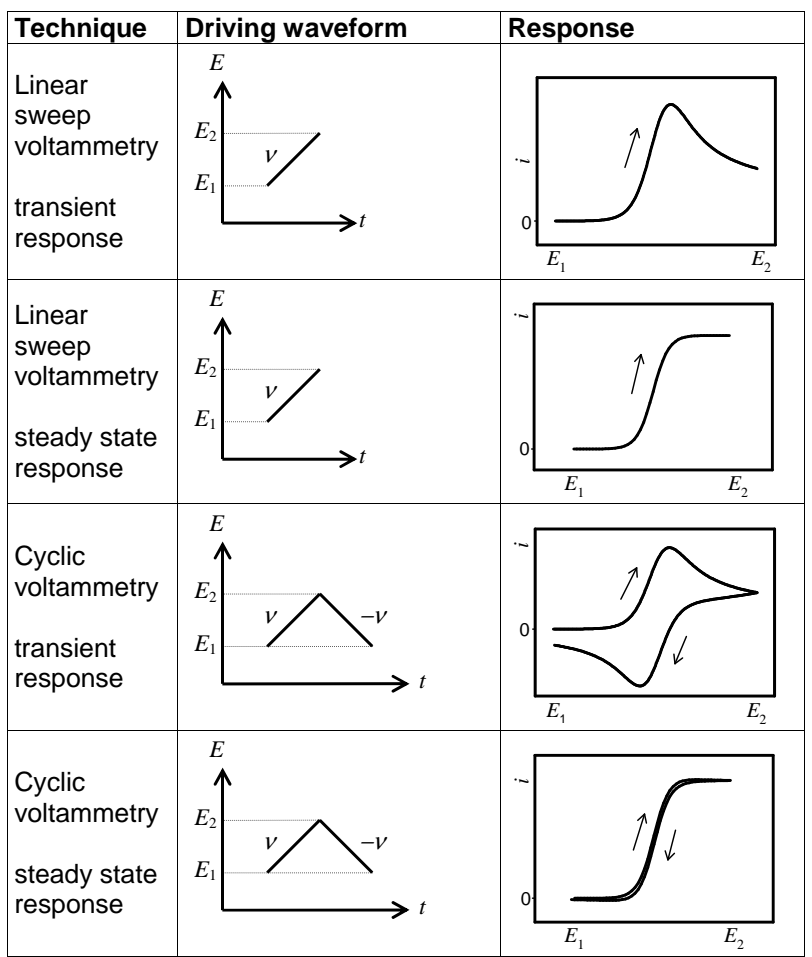

no reaction occurs to one where the reaction of interest is mass transport or kinetically controlled, see Table 3 . In this case the current is either measured at a fixed time or as a function of time. Integration of the current over time yields the charge passed which thanks to Faraday's law can be directly related to the number of moles that have reacted. The measurement of charge, known as coulometry, is the basis of some sensors, e.g. the personal blood glucose sensors used by diabetics (Lee, 2008). Another very common waveform is the potential ramp, see Table 4 . In this case the current is measured while linearly sweeping the potential between two values; the technique is known as linear sweep voltammetry and the resulting current - potential curve as a voltammogram. If a triangular waveform is used instead, the technique is known as cyclic voltammetry and the current - potential curve as a cyclic voltammogram. Voltammograms show peaks and waves which represent the different redox processes occurring in the potential window selected. The positions of the peaks and waves along the potential axis reflect the species involved (via their redox potential) but also whether the redox reactions are kinetically facile or difficult. The shape and height of the peaks and waves also indicate the nature of the redox processes (for example whether a given redox process involves an adsorption/desorption or whether both reactants and products are soluble). A voltammogram is therefore a kind of finger print of the redox reactions (and 


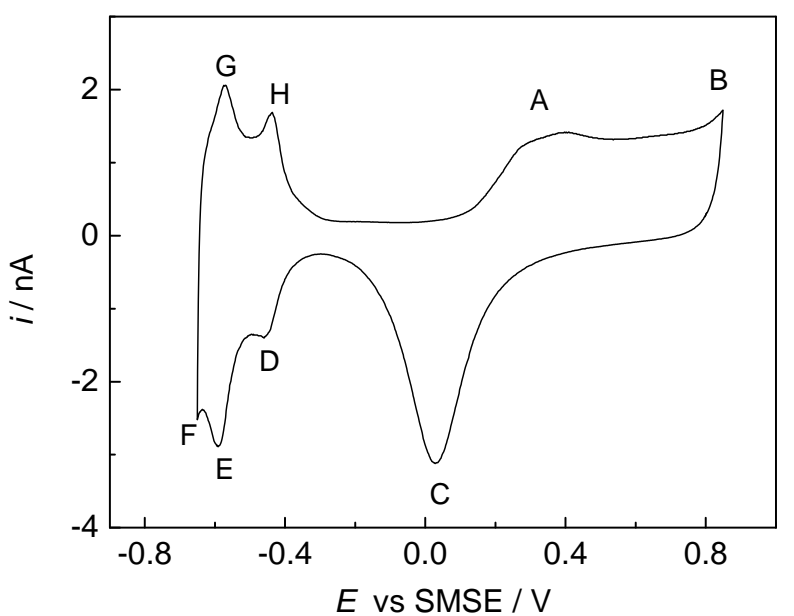

Fig. 1. A typical cyclic voltammogram recorded with a Pt microdisc ( $25 \mu \mathrm{m}$ diameter) in $1 \mathrm{M} \mathrm{H}_{2} \mathrm{SO}_{4}$ at $100 \mathrm{mV} \mathrm{s}^{-1}$. The letters indicate the redox processes taking place on the Pt surface. (A) Pt oxide formation, (B) oxygen evolution, (C) Pt oxide reduction and stripping, (D) adsorption of strongly bound hydrogen, (E) adsorption of weakly bound hydrogen, (F) hydrogen evolution, (G) desorption of weakly bound hydrogen, $(\mathbf{H})$ desorption of strongly bound hydrogen.

of the electrode material, see e.g. Fig. 1 for a typical voltammogram on a Pt electrode and Fig. 2 for that on a Pd electrode); being able to deduce from the shape and position of the voltammetric features the species involved, the nature of the reaction and what controls their kinetics is a key skill in electroanalytical chemistry. Although the focus of this article is on sensing, one should not loose sight that in amperometry the working electrode consumes and produces species. It therefore modifies the analyte, albeit very locally but this may be significant if the analyte volume is small relative to the electrode area. Nevertheless this effect may be usefully harnessed to electrochemically generate new species e.g. $\mathrm{Cl}_{2}$ to prevent biofouling or $\mathrm{H}^{+}$and $\mathrm{OH}^{-}$to control $\mathrm{pH}$.

Advanced voltammetric techniques have been developed to increase the sensitivity and selectivity of the voltammetric signal. In most cases this requires minimizing the current from non-faradaic processes such as that due to the charging and discharging of the double layer (Greef et al., 1985; Bard and Faulkner, 2001). These techniques rely on combinations of sweeps and steps, see Table 5, and have names such as staircase voltammetry, normal pulse voltammetry, differential pulse voltammetry and square wave voltammetry (Whitfield and Jagner, 1981; Bard and Faulkner, 2001; Denuault et al., 2007). A classic example of the power of sweep and step combinations is anodic stripping voltammetry where a step to low potentials is used to pre-concentrate metallic species by reducing them on the electrode (or in a mercury film predeposited on the electrode) while a subsequent sweep towards high potentials is used to oxidise them sequentially, Fig. 3. Similar techniques have been designed to extend the

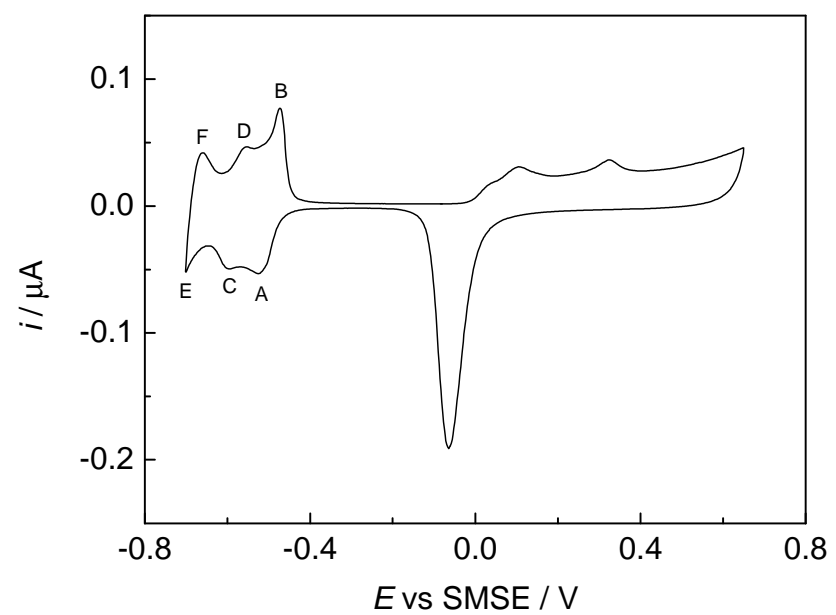

Fig. 2. Cyclic voltammogram recorded with a $\mathrm{Pd}$ microdisc ( $25 \mu$ m diameter) in a deaerated $0.5 \mathrm{M} \mathrm{Na}_{2} \mathrm{SO}_{4}+\mathrm{H}_{2} \mathrm{SO}_{4}$ solution $(\mathrm{pH}=1.88)$ at $20 \mathrm{mV} \mathrm{s}^{-1}$. The letters indicate some of the redox processes taking place on the Pd surface. (A) hydrogen adsorption, (C) hydrogen absorption to form the $\alpha$ phase, (E) the beginning of hydrogen absorption to form the $\beta$ phase, (B), (D), (F) stripping peaks corresponding to (A), (C), (E).

range of species beyond metallic compounds, e.g. cathodic stripping voltammetry and adsorptive stripping voltammetry, but all have in common that the voltammetric peak heights (or area) yield quantitative information while the peak potentials inform about the speciation (Wang, 1985). These stripping techniques constitute the most common applications of voltammetry in oceanography.

The selectivity of amperometric methods is achieved by choosing three important parameters of the electrochemical reaction: the potential to select the species of interest, the electrode material to avoid kinetic limitations and the electrolyte to limit or widen the potential window. The precision and reproducibility of amperometric methods is achieved by controlling the temperature (or correcting for temperature variations) because diffusion coefficients typically increase by $2 \%$ per Kelvin and by maintaining a clean working electrode (e.g. by choosing the $\mathrm{pH}$ to avoid precipitates or applying waveforms to recondition the electrode). The detection limit is affected by parallel redox reactions such as adsorption and oxide build up.

The next sections consider a selection of amperometric methods and for each present a brief description of the technique.

\subsection{Steady state methods}

\subsubsection{Principles}

In a typical electrochemical system, steady state currents are obtained when the rate of the overall electrochemical process is under the control of mass transport, i.e. when the arrival of 


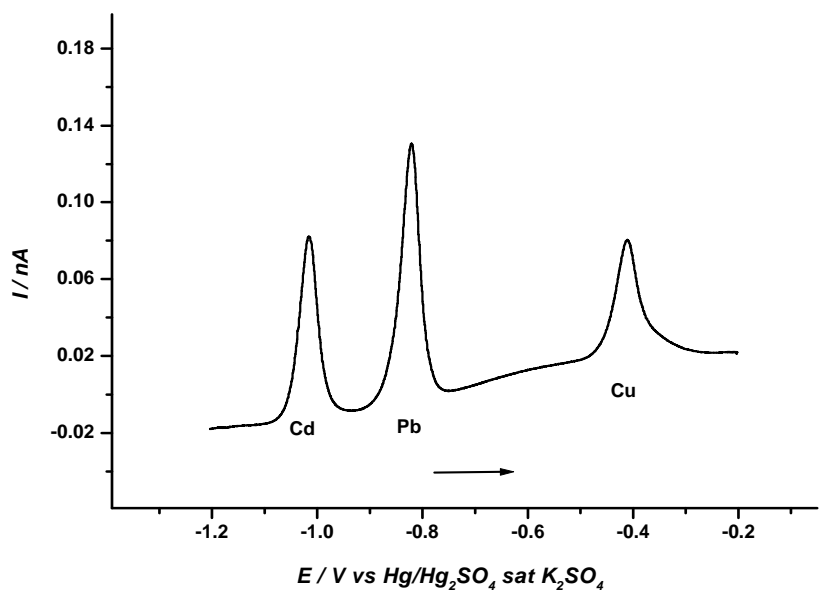

Fig. 3. Anodic stripping voltammogram recorded with a hemispherical $\mathrm{Hg}$ microelectrode ( $25 \mu \mathrm{m}$ diameter), in a solution containing $2.5 \times 10^{-7} \mathrm{M}$ of both $\mathrm{Cd}^{2+}$ and $\mathrm{Pb}^{2+}$ and $2 \times 10^{-7} \mathrm{M}$ of $\mathrm{Cu}^{2+}$ in $0.1 \mathrm{M} \mathrm{NaClO}_{4} . E_{d}=-1.2 \mathrm{~V}, t_{d}=300 \mathrm{~s}$ and sweep rate $=10 \mathrm{mV} \mathrm{s}^{-1}$.

reactants to the electrode surface determines the kinetics of the process. Three forms of mass transport are generally considered: diffusion (movement of species down a concentration gradient), convection (movement of a body of solution under a force) and migration (movement of charged species under a potential gradient). The effect of the latter is often negligible owing to the presence of large concentrations of inert electrolytes, clearly the case in sea water but not necessarily so in fresh and estuarine waters. Convection can be natural (e.g. due to density gradients) or forced (controlled as in a flow cell or unwanted as around a flowing stream or a moving CTD). Diffusion however is always present because reactants are consumed at the electrode surface. Steady state mass transport can be obtained in two ways, by controlled diffusion or by controlled hydrodynamics. Diffusion control is achieved with membrane covered electrodes (Clark Jr. et al., 1953), thin layer cells (Bard and Faulkner, 2001) and microdisc electrodes (Montenegro et al., 1991). Hydrodynamic control is achieved with rotating disc electrodes (Bard and Faulkner, 2001), channel electrodes (Cooper and Compton, 1998) and hydrodynamic modulation, e.g. with microjet electrodes (Macpherson, 2000). Some of these are now considered in more details.

\subsubsection{Membrane covered electrodes}

In this type of sensor a membrane is used to control the rate of transport of the species of interest, e.g. dissolved oxygen in the Clark electrode (Clark Jr. et al., 1953), from the analyte to an electrolyte where the redox process takes place, the reduction of oxygen in this example. The SBE43, a dissolved oxygen sensor manufactured by Sea-Bird Electronics Inc. (Carlson, 2002), is probably the electrochemical sensor most familiar to oceanographers. It is the concentra-
Table 5. Common voltammetric techniques based on digital potential waveforms shown with the corresponding amperometric responses typical of diffusion controlled processes.

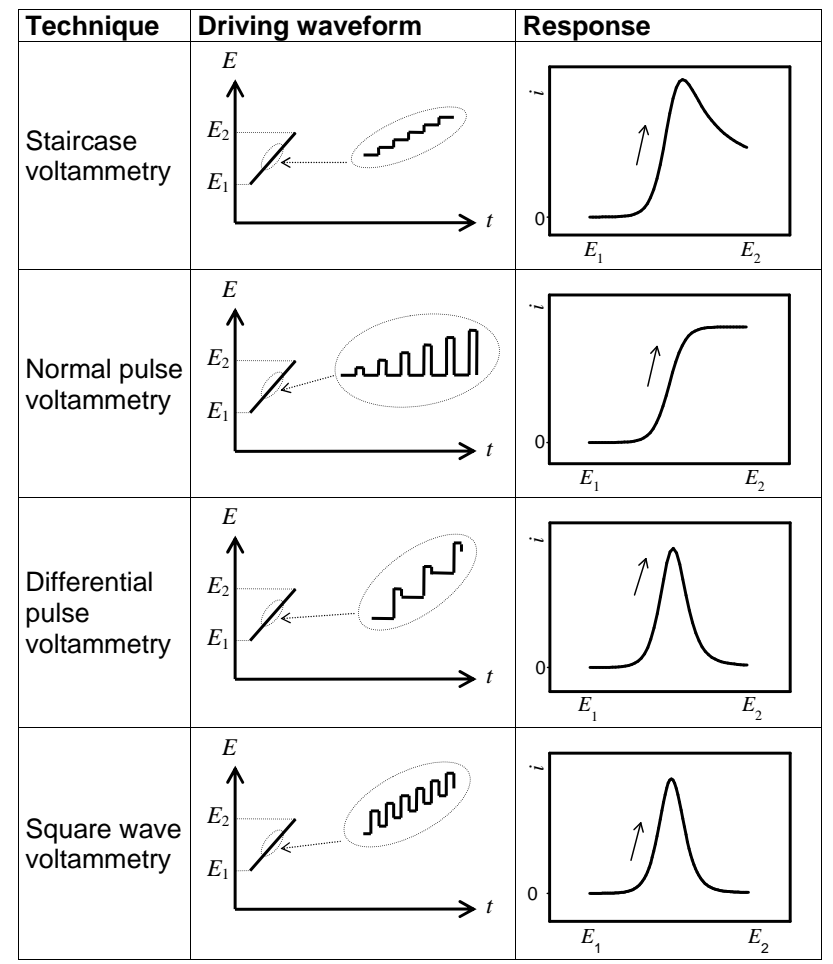

tion outside the membrane and the diffusion of the species through the membrane which determine the magnitude of the current and therefore the sensor response. A disadvantage of this approach is that the diffusion coefficient of the species of interest inside the membrane varies with the state of the membrane. This makes it difficult to derive an analytical expression for the response and requires its calibration. Worse, the membrane may change during operation, e.g. its porosity reduces with increased pressure and the operation of the sensor is typically reliable to $1000 \mathrm{~m}$ depth. Significant hysteresis between up and down casts is observed beyond this depth as shown by (Murphy et al., 2008). Another drawback of membranes is their slow response times (typically $t_{90} \geq 1 \mathrm{~s}$ ) though microelectrode membrane sensors are reported to achieve $t_{90}$ approaching $0.2 \mathrm{~s}$ (Reimers, 2007). For oxygen determination, a comparison between the performance of Clark type sensors, optodes, voltammetry and Winkler titrations has been reported by (Glazer et al., 2004). A great advantage of membrane covered electrodes is that the working electrode operates in a clean electrolyte and is thus protected from fouling. It is also protected from the effects of convection thus making the response truly diffusion controlled and allowing the sensors to be used in non quiescent conditions.

Although the electrolyte behind the diffusion barrier is usually aqueous, other electrolytes can be used. 
Concentrated acids (sulphuric, phosphoric), bases (potassium hydroxide), inorganic salts (lithium bromide and lithium chloride), organic electrolytes or organic gels are used in commercially available electrochemical gas sensors, see e.g. those from City Technology Ltd. Organic electrolytes allow the detection of species with no or complicated redox processes in aqueous media. However electrochemical reactions in organic media must often be carried out without water (even at trace levels) which is difficult to ensure since membranes always allow some water ingress. The advent of ionic liquids should facilitate the detection of species which cannot be reduced or oxidised in aqueous electrolytes, see for examples (Ji et al., 2007; Giovanelli et al., 2004) for the electrochemical detection of ammonia.

\subsubsection{Microelectrodes}

In the electrochemical literature microelectrodes are electrodes with a characteristic dimension sufficiently small to determine their amperometric properties (Montenegro et al., 1991). Microdiscs and microbands are the most common microelectrodes. The former is defined by its radius while the latter is defined by its width. Thanks to their small size, typically micrometres to tens of micrometres, microelectrodes achieve very high rates of diffusion and suffer much less from ohmic and double layer charging distortions (Stulik et al., 2000; Wightman and Wipf, 1989). Several microelectrodes, e.g. microdiscs and microrings, achieve steady state diffusion owing to their geometry; this steady state regime is established very quickly (typically a few ms for micrometre size electrodes) hence removing the need for a diffusion barrier. The limiting current obtained under these steady state conditions can be used to determine the concentration of an analyte without the need for a calibration (Abdelsalam et al., 2001; Sosna et al., 2007). Such an approach was successfully used to record dissolved oxygen profiles with a microdisc sensor mounted on a CTD (Sosna et al., 2008) however the microdisc response still suffered from convection despite the use of a stopped flow system. Attempts to remove the effect of convection on microelectrode DO sensors have been made using arrays of recessed microdiscs (Thomas et al., 1995) obtained from bundles of carbon fibres sealed in an insulator, etched in situ to form deep wells and subsequently platinised to improve the detection of oxygen (Morita and Shimizu, 1989). Termed microhole arrays these electrodes minimize the effect of convection because mass transport is controlled by the diffusion of oxygen down the well. In effect recessing the fibres creates a diffusion barrier consisting of an array of capillaries with identical diameters to that of the embedded microdisc electrodes. However the response time worsens with the depth of the well. Nevertheless microhole arrays were tested and calibrated for DO sensing on CTDs (Thomas and Atkinson, 1995; Atkinson et al., 1996).

\subsubsection{Controlled convection methods}

With these methods, well defined hydrodynamic conditions are chosen to control the flow of solution towards or parallel to the electrode and thus determine the thickness of a boundary layer within which diffusion takes place. In the laboratory the rotating disc electrode (Bard and Faulkner, 2001) is routinely used to perform electrochemical studies over a range of mass transfer kinetics. The rotation of the electrode pumps solution towards the surface of the electrode and the diffusion layer thickness is determined by the rotation rate. In electrochemical sensors the flow cell (Cooper and Compton, 1998) is the preferred design where the solution flows over the electrode. Here the flow rate determines the thickness of the diffusion layer. Other designs have been reported, some of which achieve very high rate of mass transfer (Macpherson et al., 1994). Other approaches involve modulating the hydrodynamic conditions (Macpherson, 2000).

\subsection{Transient methods}

Transient amperometry typically entails recording the time dependence of the current following the application of a potential perturbation to the working electrode. Different techniques are found depending on the type of perturbation applied.

\subsubsection{Chronoamperometry}

The simplest perturbation is a potential step, typically from a value where no redox reaction takes place to one where the reaction is mass transport or kinetically controlled. This leads to the technique known as chronoamperometry (Greef et al., 1985; Bard and Faulkner, 2001; Denuault et al., 2007) where the current is measured as a function of time following the potential step. In the laboratory it is used to derive kinetic information, e.g. the lifetime of a species involved in a chemical process. Any combination of potential steps is possible where one may vary the potentials applied and the duration of each step. This strategy may be used to generate a species electrochemically during the first step and probe it with the second step, e.g. to determine its diffusion coefficient or its half life. Alternatively one step may be used to condition or recondition the electrode surface while the other is used to perform the measurement of interest. This approach was used to recondition a microdisc electrode for the determination of dissolved oxygen (Sosna et al., 2007, 2008).

\subsubsection{Voltammetry}

In linear sweep voltammetry, the perturbation is a potential ramp where the potential is swept from a value where no reaction occurs to one where the reaction is mass transport or kinetically controlled. In cyclic voltammetry the potential is swept back and forth between the two limits. The results appear in the form of current - potential 
curves known as voltammograms (Greef et al., 1985; Bard and Faulkner, 2001; Denuault et al., 2007). Combinations of ramps and steps known as staircase voltammetry, normal pulse voltammetry, differential pulse voltammetry and square wave voltammetry provide increased sensitivity, are often used in electroanalytical chemistry and are now common on commercial electrochemical workstations (Bard and Faulkner, 2001; Denuault et al., 2007).

Voltammetry and in particular stripping voltammetry have provided new insight in the chemistry of ecosystems (Ma et al., 2007) such as sediments and water columns (Reimers, 2007) for their ability to yield quantitative determination and speciation of metals and metal complexes. In a few cases, e.g. (Luther et al., 1999) these techniques have been used on sensors, in most cases, they are used in the lab on board of the research ship. In stripping voltammetry the basic procedure involves a pre-concentration step during which soluble species adsorb on the electrode and a linear potential sweep of the electrode potential during which the species are stripped off the electrode. Depending on the nature of the analyte different modes of stripping analysis are used. Anodic stripping voltammetry employs a mercury drop electrode, a mercury film electrode (Mikkelsen et al., 2006; Luther et al., 2008) or sometimes just a bare electrode (Bartlett et al., 2000). This technique is very sensitive and allows the detection of metal ions down to $10^{-11} \mathrm{M}$ (Tercier-Waeber et al., 1999). Variants include cathodic stripping voltammetry (van den Berg et al., 1991; Obata and van den Berg, 2001; Gun et al., 2006), adsorptive stripping voltammetry and potentiometric stripping analysis (this is not voltammetry as it involves a current rather than potential sweep) and are used to extend the analysis to inorganic and organic compounds.

\subsection{Transient amperometry with microelectrodes}

Microelectrodes have been used increasingly with stripping techniques because the steady state diffusion regime greatly improves the efficiency of the pre-concentration step. Thus stripping measurements can be carried out in situ without requiring forced convection (Devitre et al., 1991; TercierWaeber et al., 1999; Abdelsalam et al., 2002). Because the electroactive area of a micrometre size electrode is very small the charging of its double layer occurs under a few $\mu$ s and it is possible to obtain useful faradaic information on time scales not available to conventional electrodes. This has been at the heart of the development of high speed voltammetry. Whereas typical sweep rates range from $1 \mathrm{mV} \mathrm{s}^{-1}$ to $1 \mathrm{~V} \mathrm{~s}^{-1}$ with conventional electrodes, the upper limit can be extended to $\mathrm{kV} \mathrm{s}^{-1}$ with common instruments and to $\mathrm{MV} \mathrm{s}^{-1}$ with purpose built electronics (Wightman and Wipf, 1989; Amatore and Maisonhaute, 2005) when using microelectrodes. This facilitates the recording of voltammograms in fast changing environments or in rapidly evolving reactions as for example near hydrothermal vents (Luther et al., 2001).
The applications of microelectrodes in ocean sensing are expected to grow. Most cases reported have tended to concentrate on long times where the steady state diffusion dominates. The ability to perform measurements on the ms time scale should lead to the deployment of microelectrode sensors operating in the transient regime. According to Reimers (Reimers, 2007), "The greatest remaining challenges associated with voltammetric microelectrode measurements are refinement of techniques to optimize sensitivity, simplify calibration, and eliminate complicated interactions that occur when multiple reactive species are oxidized or reduced at the electrode surface." The development of sensors based on microelectrode arrays, possibly involving different electrode materials, different electrode sizes and geometries, electronics programmed to operate different electrodes at different times or with different techniques should improve redundancy, robustness and ultimately the quality of the sensor response.

\subsection{Galvanostatic methods}

In the amperometric methods considered previously the electrode potential was controlled and the electrode current recorded. Experimentally this is performed with a potentiostat and the techniques are sometimes called potentiostatic methods. In galvanostatic methods the current flowing between the working and counter electrodes is imposed with a current source, a galvanostat, and the potential of the working electrode is measured against that of the reference electrode. This is akin to fixing the rate of the redox process and observing how the interfacial chemistry adjusts to match the required rate. Different current perturbations, namely steps, pulses, sweeps and triangular waves have been investigated and led to a family of techniques termed chronopotentiometry (Bard and Faulkner, 2001). In the simplest form, a current step is applied, typically from no current, i.e. with the electrode at open circuit and therefore in equilibrium with the analyte, to a value chosen to target a specific electrochemical reaction. The electrode potential is then recorded as a function of time following the application of the current step.

Amongst all the techniques controlled current methods have not attracted much interest compared to controlled potential methods and even less as the basis for electrochemical sensors. This results from the facts that their advantages, simpler theoretical treatment and circuitry (a galvanostat is easier to construct and tune than a potentiostat), do not outweigh the difficult analysis of the potential transient and the lack of selectivity arising from controlling the rate of the reactions rather than the driving force applied to them.

\section{Small amplitude perturbation methods}

Small amplitude perturbation methods purposely keep the potential change to a few $\mathrm{mV}$ to retain a linear relationship 
between the current and the electrode potential. The method usually consists in applying a sinusoidal potential perturbation to the working electrode and recording the corresponding sinusoidal current. This is the basis of conductimeters used to assess water quality and salinity (Whitfield and Jagner, 1981; Abdur Rahman et al., 2008). Of course it is possible to sweep through a range of perturbation frequencies and this leads to the method of electrochemical impedance spectroscopy or impedimetry (Macdonald, 2006; Orazem and Tribollet, 2008) where the data is presented in the form of Bode diagrams (amplitude and phase of the impedance plotted against frequency) or Nyquist plots (imaginary part of the impedance plotted against the real part with every point corresponding to a different frequency). Apart from conductimetry for the determination of salinity, see e.g. the conductivity sensor of (Larson et al., 2007) used to measure solution resistance as a proxy for chloride concentration in hot vent waters, electrochemical impedance does not appear to be used in ocean sensing. This is in part due to the fact that variations in electrochemical impedance are not chemically specific thus not suitable for chemical sensing. However, selectivity can be obtained by chemically modifying the electrode surface with chemically or biologically specific receptors in which case detection is achieved by linking the change in electrochemical impedance to binding events (Van Gerwen et al., 1998). On the other hand the analysis of electrochemical impedance is complicated by the need to fit the experimental data to equivalent electrical circuits. Electrochemical impedance sensing may find a place in microfluidic devices, for example to probe pathogens such as bacteria (Radke and Alocilja, 2004; Varshney and Li, 2008).

\section{Biosensors}

These sensors are typically potentiometric, amperometric or impedimetric. The sensing electrode is modified with a layer of biologically active material, e.g. enzymes, to achieve specificity. In the electrochemical literature the terms "modified electrodes" refer to electrodes whose surface has been modified by an additional layer. The thickness of the latter may range from one molecule thus forming a monolayer to several micrometre thick films. The layer may be chemically bonded to the electrode surface, for example with a thiol terminated molecule on a gold electrode, or vacuum deposited, sputtered, spin coated, etc... but the most common form of modification is obtained by electrodeposition (Situmorang et al., 2001). Probably the most well known and successful bioelectrochemical sensor is the blood glucose sensor which involves a glucose oxidase modified electrode (Bartlett and Toh, 2004; Lee, 2008). Despite its complexity - the device involves biochemical, chemical and electrochemical reactions all coupled to form a highly specific transducer - it is mass produced (several millions of strips per month) and used by millions of diabetic patients worldwide. Similar approaches are being investigated for other metabolites (Lee, 2008). An increasing range of biological entities are being probed electrochemically, e.g. proteins with voltammetry (Mazzei et al., 2008), aptamers with electronic aptamer sensors or aptasensors (Willner and Zayats, 2007) and DNA. Electrochemical DNA sensors are receiving significant interest (Takenaka, 2001; Drummond et al., 2003; Bakker, 2004; Kavanagh and Leech, 2006; Bakker and Qin, 2006; Odenthal and Gooding, 2007; Hajdukiewicz et al., 2009). The role of biosensors in future marine monitoring programmes was reviewed (Kröger and Law, 2005); interestingly, a large number of the articles listed focused on bioelectrochemical sensors (Metfies et al., 2005; Diercks et al., 2005, 2008b). For additional references, interested readers should consult the "Journal of Biosensors \& Bioelectronics" which is dedicated to this field and regularly reports combinations of electrode materials and manufacturing techniques, measurement techniques, biological sensing elements (ranging from whole cells to enzymes, nucleic acids, affinity ligands such as antibodies and receptors, natural or biomimetic). Other journals generally dedicated to analytical chemistry, "Analytical Chemistry", "Analytica Chimica Acta", "Analytical Letters", also publish articles on bioelectrochemical sensors.

\section{$7 \quad$ Future trends}

Predicting the future is a difficult exercise at the best of times. Nevertheless it is a useful one if only to trigger new ideas. Before considering the future it is helpful to recall past predictions. Whitfield and Jagner (1981) predicted that the development of microprocessor driven electrochemical instrumentation was going to have a significant impact in marine electrochemistry. Yes modern sensors often incorporate a CPU to control a range of functions but this has not revolutionised the applications of electrochemistry in ocean sensing. They also expected that the microprocessor would lead to intelligent devices capable of switching between electrochemical techniques depending on the sample. This has not been the case. In fact it is probably fair to say that the electrochemical measurements routinely performed in ocean sensing are rather simple and that few research groups have taken the challenge of implementing more advanced electroanalytical methods such as pulsed amperometric techniques. The predicted developments probably did not occur because of two factors. On the technical side the electrode-solution interface is difficult to keep pristine and this quickly affects the reliability of the sensor. In the lab electrochemists regularly polish their electrodes between experiments; this is not easily, reproducibly and remotely done in the field. On the human side the interpretation of electrochemical data such as voltammograms is still a challenge and no doubt a key limiting factor in the development of electroanalytical methods in ocean sensing. For these reasons the predictions made below 
are rather incremental, short to medium term and mostly technically driven.

Arrays of electrochemical sensors will be more common. Arrays of identical sensors will provide the necessary redundancy required for long term deployments. They will also provide a source of fresh pristine electrodes sequentially exposed to the analyte until all the electrodes in the array have been used. Alternatively they will be used to implement rapid measurements where individually addressable electrodes will operate in parallel but time-shifted. Arrays of non specific electrochemical sensors analogous to electronic tongues will see increasing use in ocean sensing. They will provide chemical patterns characteristic of the sample and will thus be used to monitor the state of a body of water. These sensor arrays do not have the quantitative characteristics of traditional sensors and will therefore not be used to perform accurate measurements. The arrays will be increasingly complex and include potentiometric, amperometric and impedimetric electrochemical sensors. These arrays are traditionally understood as covering a few centimetre squares but there is no reason why large electrode arrays, e.g. on nets, could not be used to provide large 2-D vertical or horizontal cross sections. This is not restricted to electrochemical sensors but the latter are inherently cheap and therefore amenable to large scale deployments.

Microelectrodes are likely to see increasing use especially when combined with microfluidics which provides control over sampling, flow rates, mixing, addition of reagents, etc... This will be in combination with larger electrodes used to generate reagents in situ, e.g. $\mathrm{H}^{+}$or $\mathrm{OH}^{-}$, for chemical analysis or dissolved $\mathrm{Cl}_{2}$ to prevent biofouling within the device.

As well as the need for self cleaning of the electrode, the need for in situ calibration will be more acute. While the electronics can already be designed to self calibrate (Prien, 2007), electrochemical sensors will need to be developed to include self calibration of the electrode response.

In the short term specific bioelectrochemical sensors will become more widespread and perform electrochemical bioassays for example to detect water born pathogens (Fritsch et al., 2008) and toxic algae (Diercks et al., 2008a), water quality assessment (Tonning et al., 2005) and general environmental monitoring (Marrazza et al., 1999). In the medium term, arrays of bioelectrochemical sensors could have applications in biochemical finger printing.

The combination of microfluidics with electroanalytical methods will make it possible to detect in situ species which are currently analysed electrochemically in the lab, e.g. labile Fe (Mikkelsen et al., 2006), Co (Vega and van den Berg, 1997), Ni, Sb, V, Se, Sn, U (van den Berg et al., 1991) and the list of species detected with electrochemical sensors will grow beyond $\mathrm{H}^{+}$(Reimers, 2007), dissolved oxygen, heavy metals where some of the sensors are at a technology readiness level of 7 with the detection of $\mathrm{Cu}, \mathrm{Pb}$ and $\mathrm{Cd}$ concentrations at sub nM levels (Tercier-Waeber et al., 1999), carbonates (Choi et al., 2002), silicates (Lacombe et al., 2007), in situ speciation of $\mathrm{Mn}, \mathrm{Fe}$ and in $\mathrm{S}$ compounds (Luther et al., 1998; Rozan et al., 1999, 2000).

\section{Conclusions}

The main objective of this review was to consider the different electroanalytical techniques currently available, review their principles, consider their existing, in development and future applications in ocean sensing and identify the challenges ahead. A second objective was to gaze in the electrochemical ball, identify topics currently reported in the electrochemical literature which could lead to improved sensors or to new chemical species being sensed and if possible to discover emerging technologies. In situ amperometry and voltammetry with microelectrodes have already brought a wealth of spatially and temporally resolved new data; they are destined to take a greater place in the panoply of ocean sensors however the technological difficulties in packaging the devices, the improvement required in accuracy and precision, the need to recondition the electrodes in situ, the need to have built-in calibration and above all the need to educate the community to work with microelectrodes and analyse the resulting voltammetric data (Reimers, 2007) have limited the progress of these techniques up the technology readiness ladder. These hurdles will need to be addressed and first and foremost adequately funded. Electrodes can be modified with different sensing layers and can be made to sense biological entities. This is routinely carried out in the lab and in biomedical sensing and is therefore an area worthy of consideration for ocean sensing.

Acknowledgements. Matt Mowlem (NOCS, Southampton, UK), Robin Pascal (NOCS, Southampton, UK) and Ralf Prien (IOW, Warnemünde, Germany) are gratefully thanked for introducing the author to ocean sensing and for faithfully collaborating over many years.

Edited by: R. Prien

\section{References}

Abdelsalam, M. E., Denuault, G., Baldo, M. A., Bragato, C., and Daniele, S.: Detection of hydroxide ions in aqueous solutions by steady- state voltammetry, Electroanal, 13, 289-294, 2001.

Abdelsalam, M. E., Denuault, G., and Daniele, S.: Calibrationless determination of cadmium, lead and copper in rain samples by stripping voltammetry at mercury microelectrodes - Effect of natural convection on the deposition step, Anal. Chim. Acta, 452, 65-75, 2002.

Abdur Rahman, A. R., Bhat, S., and Bhansali, S.: Design, fabrication, and impedance characterization of a capacitance-based salinity sensor for marine applications, J. Electrochem. Soc., 155, 355-360, 2008.

Amatore, C. and Maisonhaute, E.: When voltammetry reaches nanoseconds, Anal. Chem., 77, 303A-311A, 2005. 
Atkinson, M. J., Thomas, F. I. M., and Larson, N.: Effects of pressure on oxygen sensors, J. Atmos. Ocean. Tech., 13, 1267-1274, 1996.

Bakker, E. and Telting-Diaz, M.: Electrochemical sensors, Anal. Chem., 74, 2781-2800, 2002.

Bakker, E.: Electrochemical sensors, Anal. Chem., 76, 3285-3298, 2004

Bakker, E. and Qin, Y.: Electrochemical sensors, Anal. Chem., 78, 3965-3983, 2006.

Bakker, E. and Pretsch, E.: Modern Potentiometry, Angewandte Chemie-International Edition, 46, 5660-5668, 2007.

Bard, A. J. and Faulkner, L. R.: Electrochemical methods: Fundamentals and Applications, 2nd ed., Wiley, New York, 2001.

Bartlett, P. N., Birkin, P. R., Wang, J. H., Palmisano, F., and De Benedetto, G.: An enzyme switch employing direct electrochemical communication between horseradish peroxidase and a poly(aniline) film, Anal. Chem., 70, 3685-3694, 1998.

Bartlett, P. N., Denuault, G., and Sousa, M. F. B.: A study of the preconcentration and stripping voltammetry of $\mathrm{Pb}$ (II) at carbon electrodes, Analyst, 125, 1135-1138, 2000.

Bartlett, P. N. and Toh, C. S.: in: Biosensors: A Practical approach, 2nd ed., edited by: Cooper, J., and Cass, A. E. G., OUP, Oxford, 59-96, 2004.

Bezbaruah, A. N. and Zhang, T. C.: Fabrication of anodically electrodeposited iridium oxide film $\mathrm{pH}$ microelectrodes for microenvironmental studies, Anal. Chem., 74, 5726-5733, 2002.

Bobacka, J., Ivaska, A., and Lewenstam, A.: Potentiometric ion sensors based on conducting polymers, Electroanal, 15, 366374, 2003.

Carlson, J.: Development of an Optimized Dissolved Oxygen Sensor for Oceanographic Profiling, International Ocean Systems, 6, September/October 2002, online available at: http://www. intoceansys.co.uk/ 2002.

Choi, Y. S., Lvova, L., Shin, J. H., Oh, S. H., Lee, C. S., Kim, B. H., Cha, G. S., and Nam, H.: Determination of oceanic carbon dioxide using a carbonate- selective electrode, Anal. Chem., 74, 2435-2440, 2002.

Clark Jr., L. C., Wolf, R., Granger, D., and Taylor, Z.: Continuous recording of blood oxygen tensions by polarography, J. Appl. Physiol., 6, 189-193, 1953.

Clegg, S. L. and Whitfield, M.: A Chemical-Model of Seawater Including Dissolved Ammonia and the Stoichiometric Dissociation-Constant of Ammonia in Estuarine Water and Seawater from -2-Degrees-C to 40-Degrees-C, Geochim. Cosmochim. Acta, 59, 2403-2421, 1995.

Compton, R. G. and Sanders, G. H. V.: Electrode potentials, Oxford Chemistry Primers, Oxford, Oxford, 92 pp., 1996.

Cooper, J. A. and Compton, R. G.: Channel electrodes - A review, Electroanal, 10, 141-155, 1998.

Cosnier, S., Stoytcheva, M., Senillou, A., Perrot, H., Furriel, R. P. M., and Leone, F. A.: A biotinylated conducting polypyrrole for the spatially controlled construction of an amperometric biosensor, Anal. Chem., 71, 3692-3697, 1999.

De Marco, R., Clarke, G., and Pejcic, B.: Ion-selective electrode potentiometry in environmental analysis, Electroanal, 19, 19872001, 2007.

Denuault, G., Sosna, M., and Williams, K.-J.: Classical Experiments, in: Handbook of Electrochemistry, edited by: Zoski, C. G., Elsevier, Amsterdam, 431-469, 2007.
Devitre, R. R., Tercier, M. L., Tsacopoulos, M., and Buffle, J.: Preparation and Properties of a Mercury-Plated Iridium-Based Microelectrode, Anal. Chim. Acta, 249, 419-425, 1991.

Dhawan, S. K., Kumar, D., Ram, M. K., Chandra, S., and Trivedi, D. C.: Application of conducting polyaniline as sensor material for ammonia, Sens. Actuator B-Chem., 40, 99-103, 1997.

Diercks, S., Metfies, K., and Medlin, L. K.: Development of a rRNA-Biosensor for the detection of toxic algae (EU-Project ALGADEC), Phycologia, 44, 28-28, 2005.

Diercks, S., Metfies, K., and Medlin, L. K.: Development and adaptation of a multiprobe biosensor for the use in a semi-automated device for the detection of toxic algae, Biosens. Bioelectron., 23, 1527-1533, 2008a.

Diercks, S., Metfies, K., Schroder, F., Medlin, L. K., and Colijn, F. Detection of phytoplankton with nucleic acid sensors, Algal Toxins: Nature, Occurrence, Effect and Detection, 285-299, 2008b.

Ding, K., Seyfried, W. E., Tivey, M. K., and Bradley, A. M.: In situ measurement of dissolved $\mathrm{H}-2$ and $\mathrm{H} 2 \mathrm{~S}$ in high-temperature hydrothermal vent fluids at the Main Endeavour Field, Juan de Fuca Ridge, Earth Planet. Sci. Lett., 186, 417-425, 2001.

Ding, K. and Seyfried, W. E.: In situ measurement of $\mathrm{pH}$ and dissolved $\mathrm{H}-2$ in mid-ocean ridge hydrothermal fluids at elevated temperatures and pressures, Chem. Rev., 107, 601-622, 2007.

Drummond, T. G., Hill, M. G., and Barton, J. K.: Electrochemical DNA sensors, Nat. Biotechnol., 21, 1192-1199, 2003.

Dubbe, A.: Fundamentals of solid state ionic micro gas sensors, Sens. Actuator B-Chem., 88, 138-148, 2003.

Evans, S. A. G., Elliott, J. M., Andrews, L. M., Bartlett, P. N., Doyle, P. J., and Denuault, G.: Detection of hydrogen peroxide at mesoporous platinum microelectrodes, Anal. Chem., 74, 1322-1326, 2002.

Fritsch, I., Beitle, R., and Aguilar, Z.: Electrochemical method for detecting water born pathogens, US 07456028, 25 November 2008, 2008.

Gale, P. A.: Synthetic indole, carbazole, biindole and indolocarbazole-based receptors: applications in anion complexation and sensing, Chem. Commun., 4525-4540, 2008.

Giovanelli, D., Buzzeo, M. C., Lawrence, N. S., Hardacre, C., Seddon, K. R., and Compton, R. G.: Determination of ammonia based on the electro-oxidation of hydroquinone in dimethylformamide or in the room temperature ionic liquid, 1-ethyl-3methylimidazolium bis(trifluoromethylsulfonyl)imide, Talanta, 62, 904-911, 2004.

Glazer, B. T., Marsh, A. G., Stierhoff, K., and Luther, G. W.: The dynamic response of optical oxygen sensors and voltammetric electrodes to temporal changes in dissolved oxygen concentrations, Anal. Chim. Acta, 518, 93-100, 2004.

Greef, R., Peat, R., Peter, L. M., Pletcher, D., and Robinson, J.: Instrumental Methods in Electrochemistry, Ellis Horwood, Chichester, 443 pp., 1985.

Grundig, B., Wittstock, G., Rudel, U., and Strehlitz, B.: MediatorModified Electrodes for Electrocatalytic Oxidation of NADH, J. Electroanal. Chem., 395, 143-157, 1995.

Gun, J., Salaun, P., and van den Berg, C. M. G.: Advantages of using a mercury coated, micro-wire, electrode in adsorptive cathodic stripping voltammetry, Anal. Chim. Acta, 571, 86-92, 2006.

Hajdukiewicz, J., Boland, S., Kavanagh, P., Nowicka, A., Stojek, Z., and Leech, D.: Enzyme-Amplified Amperometric Detection 
of DNA Using Redox Mediating Films on Gold Microelectrodes, Electroanal., 21, 342-350, 2009.

Hassan, S. S. M., Marzouk, S. A. M., and Badawy, N. M.: Solid state iridium oxide-titanium based sensor for flow injection $\mathrm{pH}$ measurements, Anal. Lett., 35, 1301-1311, 2002.

Hong, M., Jianguo, W., Jing, G., and Ping, W.: On board-ship seawater heavy metal automatic measurement system based on electronic tongue, Sixth World Congress on Intelligent Control and Automation (IEEE Cat. No. 06EX1358C), 4 pp., CD-ROM, 2006.

Horrocks, B. R., Mirkin, M. V., Pierce, D. T., Bard, A. J., Nagy, G., and Toth, K.: Scanning Electrochemical Microscopy .19. IonSelective Potentiometric Microscopy, Anal. Chem., 65, 12131224, 1993.

Imokawa, T., Williams, K.-J., and Denuault, G.: Fabrication and Characterization of Nanostructured Pd Hydride $\mathrm{pH}$ Microelectrodes, Anal. Chem., 78, 265-271, 2006.

Ji, X. B., Banks, C. E., Silvester, D. S., Wain, A. J., and Compton, R. G.: Electrode kinetic studies of the hydroquinone-benzoquinone system and the reaction between hydroquinone and ammonia in propylene carbonate: Application to the indirect electroanalytical sensing of ammonia, J. Phys. Chem. C, 111, 1496-1504, 2007.

Kavanagh, P. and Leech, D.: Redox polymer and probe DNA tethered to gold electrodes for enzyme-amplified amperometric detection of DNA hybridization, Anal. Chem., 78, 2710-2716, 2006.

Kharitonov, A. B., Zayats, M., Lichtenstein, A., Katz, E., and Willner, I.: Enzyme monolayer-functionalized field-effect transistors for biosensor applications, Sens. Actuator B-Chem., 70, 222231, 2000.

Kröger, S. and Law, R. J.: Sensing the sea, Trends Biotechnol., 23, 250-256, 2005.

Lacombe, M., Garcon, V., Comtat, M., Oriol, L., Sudre, J., Thouron, D., Le Bris, N., and Provost, C.: Silicate determination in sea water: Toward a reagentless electrochemical method, Mar. Chem., 106, 489-497, 2007.

Larson, B. I., Olson, E. J., and Lilley, M. D.: In situ measurement of dissolved chloride in high temperature hydrothermal fluids, Geochim. Cosmochim. Acta, 71, 2510-2523, 2007.

Le Bris, N., Sarradin, P. M., and Pennec, S.: A new deep-sea probe for in situ $\mathrm{pH}$ measurement in the environment of hydrothermal vent biological communities, Deep-Sea Res. I, 48, 1941-1951, 2001.

Lee, T. M. H.: Over-the-counter biosensors: Past, present, and future, Sensors, 8, 5535-5559, 2008.

Luther, G. W., Brendel, P. J., Lewis, B. L., Sundby, B., Lefrancois, L., Silverberg, N., and Nuzzio, D. B.: Simultaneous measurement of O-2, Mn, Fe, I-, and S(-II) in marine pore waters with a solid-state voltammetric microelectrode, Limnol. Oceanogr., 43, 325-333, 1998.

Luther, G. W., Reimers, C. E., Nuzzio, D. B., and Lovalvo, D.: In situ deployment of voltammetric, potentiometric. and amperometric microelectrodes from a ROV to determine dissolved O-2, $\mathrm{Mn}, \mathrm{Fe}, \mathrm{S}(-2)$, and $\mathrm{pH}$ in porewaters, Environ. Sci. Technol., 33, 4352-4356, 1999.

Luther, G. W., Rozan, T. F., Taillefert, M., Nuzzio, D. B., Di Meo, C., Shank, T. M., Lutz, R. A., and Cary, S. C.: Chemical speciation drives hydrothermal vent ecology, Nature, 410, 813-816,
2001.

Luther, G. W., Glazer, B. T., Ma, S. F., Trouwborst, R. E., Moore, T. S., Metzger, E., Kraiya, C., Waite, T. J., Druschel, G., Sundby, B., Taillefert, M., Nuzzio, D. B., Shank, T. M., Lewis, B. L., and Brendel, P. J.: Use of voltammetric solid-state (micro)electrodes for studying biogeochemical processes: Laboratory measurements to real time measurements with an in situ electrochemical analyzer (ISEA), Mar. Chem., 108, 221-235, 2008.

Ma, S., Luther, G. W., Scarborough, R. W., and Mensinger, M. G.: Voltammetry: An in situ tool to monitor the health of ecosystems, Electroanal., 19, 2051-2058, 2007.

Macdonald, D. D.: Reflections on the history of electrochemical impedance spectroscopy, Electrochim. Acta, 51, 1376-1388, 2006.

Macpherson, J. V., Marcar, S., and Unwin, P. R.: Microjet Electrode - a Hydrodynamic Ultramicroelectrode with High Mass-Transfer Rates, Anal. Chem., 66, 2175-2179, 1994.

Macpherson, J. V.: Recent advances in hydrodynamic modulation voltammetry, Electroanal., 12, 1001-1011, 2000.

Marrazza, G., Chianella, I., and Mascini, M.: Disposable DNA electrochemical biosensors for environmental monitoring, Anal. Chim. Acta, 387, 297-307, 1999.

Marzouk, S. A. M., Ufer, S., Buck, R. P., Johnson, T. A., Dunlap, L. A., and Cascio, W. E.: Electrodeposited iridium oxide $\mathrm{pH}$ electrode for measurement of extracellular myocardial acidosis during acute ischemia, Anal. Chem., 70, 5054-5061, 1998.

Mazzei, F., Favero, G., Frasconi, M., Tata, A., Tuccitto, N., Licciardello, A., and Pepi, F.: Soft-landed protein voltammetry: A tool for redox protein characterization, Anal. Chem., 80, 5937-5944, 2008.

Men, H., Zou, S. F., Li, Y., Wang, Y. P., Ye, X. S., and Wang, P.: A novel electronic tongue combined MLAPS with stripping voltammetry for environmental detection, Sens. Actuator B-Chem., 110, 350-357, 2005.

Metfies, K., Huljic, S., Lange, M., and Medlin, L. K.: Electrochemical detection of the toxic dinoflagellate Alexandrium ostenfeldii with a DNA-biosensor, Biosens. Bioelectron., 20, 1349-1357, 2005.

Mikkelsen, O., van den Berg, C. M. G., and Schroder, K. H.: Determination of labile iron at low nmol L-1 levels in estuarine and coastal waters by anodic stripping voltammetry, Electroanal., 18, 35-43, 2006.

Montenegro, M. I., Queirós, M. A., and Daschbach, J. L.: Microelectrodes: Theory and Applications, NATO ASI Series, Series E: Applied Science, Kluwer Academic Publishers, 497 pp., 1991.

Morita, K. and Shimizu, Y.: Microhole Array for OxygenElectrode, Anal. Chem., 61, 159-162, 1989.

Murphy, D. J., Larson, N. G., and Edwards, B. C.: Improvements to the SBE 43 Oxygen Calibration Algorithm, Sea-Bird Electronics Inc., Bellevue, WA, USA, 2008.

Obata, H. and van den Berg, C. M. G.: Determination of picomolar levels of iron in seawater using catalytic cathodic stripping voltammetry, Anal. Chem., 73, 2522-2528, 2001.

Odenthal, K. J., and Gooding, J. J.: An introduction to electrochemical DNA biosensors, Analyst, 132, 603-610, 2007.

Orazem, M. E. and Tribollet, B.: Electrochemical Impedance Spectroscopy, The Electrochemical Society series, WileyInterscience, 523 pp., 2008.

Prien, R., Pascal, R., Mowlem, M., Denuault, G., and Sosna, M.: 
Development and first results of a new fast response microelectrode DO-sensor, in: Oceans 2005 - Europe, Vols. 1 and 2, 744 747, 2005

Prien, R. D., Pascal, R. W., Attard, G. S., Birkin, P. R., Denuault, G., Cook, D., and Offin, D.: Development and first Results of a new mesoporous Microelectrode DO- Sensor, in: Oceans 2001 Mts/Ieee: An Ocean Odyssey, Vols. 1-4, Conference Proceedings, 1910-1914, 2001.

Prien, R. D.: The future of chemical in situ sensors, Mar. Chem., 107, 422-432, 2007.

Privett, B. J., Shin, J. H., and Schoenfisch, M. H.: Electrochemical sensors, Anal. Chem., 80, 4499-4517, 2008.

Radke, S. M. and Alocilja, E. C.: Design and fabrication of a microimpedance biosensor for bacterial detection, IEEE Sens. J., 4, 434-440, 2004.

Reimers, C. E.: Applications of microelectrodes to problems in chemical oceanography, Chem. Rev., 107, 590-600, 2007.

Rozan, T. F., Benoit, G., and Luther, G. W.: Measuring metal sulfide complexes in oxic river waters with square wave voltammetry, Environ. Sci. Technol., 33, 3021-3026, 1999.

Rozan, T. F., Theberge, S. M., and Luther, G.: Quantifying elemental sulfur (S-0), bisulfide (HS-) and polysulfides (S-x(2-)) using a voltammetric method, Anal. Chim. Acta, 415, 175-184, 2000.

Rudnitskaya, A., Legin, A., Seleznev, B., Kirsanov, D., and Vlasov, Y.: Detection of ultra-low activities of heavy metal ions by an array of potentiometric chemical sensors, Microchim. Acta, 163, 71-80, 2008.

Shitashima, K., Koike, Y., Kyo, M., and Hemmi, A.: Development of electrochemical in-situ $\mathrm{pH}$-pCO/sub 2/sensor for deepsea oceanography applications, 2008 IEEE Sensors, 1414-1417, 2008.

Simonian, A. L., Flounders, A. W., and Wild, J. R.: FET-based biosensors for the direct detection of organophosphate neurotoxins, Electroanal., 16, 1896-1906, 2004.

Situmorang, M., Gooding, J. J., Hibbert, D. B., and Barnett, D.: Development of potentiometric biosensors using electrodeposited polytyramine as the enzyme immobilization matrix, Electroanal., 13, 1469-1474, 2001.

Sosna, M., Denuault, G., Pascal, R. W., Prien, R. D., and Mowlem, M.: Development of a reliable microelectrode dissolved oxygen sensor, Sensors and Actuators B: Chemical, 123, 344-351, 2007.

Sosna, M., Denuault, G., Pascal, R. W., Prien, R. D., and Mowlem, M.: Field assessment of a new membrane-free microelectrode dissolved oxygen sensor for water column profiling, Limnol. Oceanogr. Methods, 6, 180-189, 2008.

Stulik, K., Amatore, C., Holub, K., Marecek, V., and Kutner, W.: Microelectrodes. Definitions, characterization, and applications (Technical Report), Pure Appl. Chem., 72, 1483-1492, 2000.

Taillefert, M., Luther, G. W., and Nuzzio, D. B.: The application of electrochemical tools for in situ measurements in aquatic systems, Electroanal., 12, 401-412, 2000.

Takenaka, S.: Highly sensitive probe for gene analysis by electrochemical approach, B Chem. Soc. Jpn., 74, 217-224, 2001.

Tercier-Waeber, M. L., Belmont-Hebert, C., Buffle, J., Graziottin, F., Fiaccabrino, G. C., and Koudelka-Hep, M.: A novel probe and microsensors for in situ, continuous, automatic profiling of trace elements in natural waters, in: IEEE Oceanic Engineering Society. OCEANS'98. Conference Proceedings, 952, 956-959, 1998.
Tercier-Waeber, M. L., Buffle, J., Confalonieri, F., Riccardi, G., Sina, A., Graziottin, F., Fiaccabrino, G. C., and KoudelkaHep, M.: Submersible voltammetric probes for in situ real-time trace element measurements in surface water, groundwater and sediment-water interface, Meas. Sci. Technol., 10, 1202-1213, 1999.

Thomas, F. I. M. and Atkinson, M. J.: Field Calibration of a Microhole Potentiostatic Oxygen Sensor for Oceanic CTDs, J. Atmos. Ocean. Tech., 12, 390-394, 1995.

Thomas, F. I. M., McCarthy, S. A., Bower, J., Krothapalli, S., Atkinson, M. J., and Flament, P.: Response Characteristics of 2 Oxygen Sensors for Oceanic CTDs, J. Atmos. Ocean. Tech., 12, 687690, 1995.

Thomas, R. C.: Ion-Sensitive Intracellular Microelectrodes: How to Make and Use Them Biological techniques series, Academic Press, London, 123 pp., 1979.

Tonning, E., Sapelnikova, S., Christensen, J., Carlsson, C., WintherNielsen, M., Dock, E., Solna, R., Skladal, P., Norgaard, L., Ruzgas, T., and Emneus, J.: Chemometric exploration of an amperometric biosensor array for fast determination of wastewater quality, Biosens. Bioelectron., 21, 608-617, 2005.

Trojanowicz, M., Lewenstam, A., Krawczyk, T. K. V., Lahdesmaki, I., and Szczepek, W.: Flow injection amperometric detection of ammonia using a polypyrrole-modified electrode and its application in urea and creatinine biosensors, Electroanal., 8, 233-243, 1996.

van den Berg, C. M. G., Khan, S. H., Daly, P. J., Riley, J. P., and Turner, D. R.: An Electrochemical Study of Nickel Antimony, Selenium, Tin, Uranium and Vanadium in the Estuary of the Tamar England Uk, Estuar. Coast. Shelf Sci., 33, 309-322, 1991.

Van Gerwen, P., Laureyn, W., Laureys, W., Huyberechts, G., De Beeck, M. O., Baert, K., Suls, J., Sansen, W., Jacobs, P., Hermans, L., and Mertens, R.: Nanoscaled interdigitated electrode arrays for biochemical sensors, Sens. Actuator B-Chem., 49, 73 80, 1998.

Varshney, M. and Li, Y. B.: Double interdigitated array microelectrode-based impedance biosensor for detection of viable Escherichia coli O157: H7 in growth medium, Talanta, 74, 518-525, 2008.

Vega, M. and van den Berg, C. M. G.: Determination of cobalt in seawater by catalytic adsorptive cathodic stripping voltammetry, Anal. Chem., 69, 874-881, 1997.

Wang, J.: Stripping Analysis: Principles, Instrumentation, and Applications Vch Pub (1985), 160 pp., 1985.

Whitfield, M. and Jagner, D.: Marine electrochemistry: A practical introduction, Wiley, 542 pp., 1981.

Wightman, R. M. and Wipf, D. O.: Voltammetry at Ultramicroelectrodes, Electroanal. Chem., 15, 267-353, 1989.

Willner, I. and Zayats, M.: Electronic aptamer-based sensors, Angewandte Chemie-International Edition, 46, 6408-6418, 2007.

Wipf, D. O., Ge, F. Y., Spaine, T. W., and Bauer, J. E.: Microscopic measurement of $\mathrm{pH}$ with iridium oxide microelectrodes, Anal. Chem., 72, 4921-4927, 2000. 